\title{
Shifts in isotopic signatures of animals with complex life-cycles can complicate conclusions on cross-boundary trophic links
}

\author{
Journal Article \\ Author(s): \\ Alp, Maria; Peckarsky, Barbara L.; Bernasconi, Stefano M.; Robinson, Christopher T. \\ Publication date: \\ 2013-10 \\ Permanent link: \\ https://doi.org/10.3929/ethz-b-000071873 \\ Rights / license: \\ In Copyright - Non-Commercial Use Permitted \\ Originally published in: \\ Aquatic Sciences 75(4), https://doi.org/10.1007/s00027-013-0303-x
}




\title{
Shifts in isotopic signatures of animals with complex life-cycles can complicate conclusions on cross-boundary trophic links
}

\author{
Maria Alp • Barbara L. Peckarsky • \\ Stefano M. Bernasconi • Christopher T. Robinson
}

Received: 18 January 2013/Accepted: 12 July 2013/Published online: 28 July 2013

(C) Springer Basel 2013

\begin{abstract}
Stable isotopes $\left({ }^{13} \mathrm{C}\right.$ and $\left.{ }^{15} \mathrm{~N}\right)$ are widely applied in studies of trophic links. We used this method to investigate the contribution of aquatic and terrestrial prey to the diet of riparian predatory arthropods in two mountain headwater streams in Colorado, USA. Aquatic and terrestrial prey and riparian predators were collected during summer 2009. To evaluate the reliability of conclusions based on stable isotope ratios, we compared the isotopic signatures of aquatic larval and terrestrial adult stages of three abundant stream insect species and assessed variation in mixing model estimates for spider diet composition
\end{abstract}

Electronic supplementary material The online version of this article (doi:10.1007/s00027-013-0303-x) contains supplementary material, which is available to authorized users.

\section{Alp $(\bowtie)$}

Department of Ecosystem Research, Leibniz-Institute

of Freshwater Ecology and Inland Fisheries (IGB),

12587 Berlin, Germany

e-mail: maria.alp@igb-berlin.de

M. Alp · C. T. Robinson

Department of Aquatic Ecology, Eawag,

8600 Dübendorf, Switzerland

M. Alp · C. T. Robinson

Institute of Integrative Biology, ETH Zürich,

8092 Zürich, Switerzland

\section{B. L. Peckarsky}

Rocky Mountain Biological Laboratory,

Crested Butte, CO, USA

B. L. Peckarsky

Departments of Zoology and Entomology,

University of Wisconsin, Madison, WI, USA

S. M. Bernasconi

Geological Institute, ETH Zentrum, 8092 Zurich, Switzerland under varying assumptions for trophic fractionation. Adult isotopic signatures of some aquatic prey species were indistinguishable from those of prey species with exclusively terrestrial life histories (stoneflies: ${ }^{13} \mathrm{C}$ and ${ }^{15} \mathrm{~N}$, chironomids: ${ }^{13} \mathrm{C}$ ). Other prey had distinctly aquatic isotopic signatures as both larvae and adults (a mayfly and a caddisfly). There was no evidence that prey with aquatic isotopic signatures contributed to the diet of the spiders near one stream. For the other stream, mixing model analysis suggested that chironomids were included in the diets of lycosid, linyphiid and liocranid spiders. Reliable estimates of the contributions of prey sources were compromised by the sensitivity of mixing models to assumptions on trophic fractionation and the presence of "isotopically cryptic" prey. This study emphasizes the importance of supporting isotope-based studies on crossboundary trophic links with data on isotopic shifts in prey with complex life cycles and assessment of fractionation rates specific to the study system.

Keywords Stream insects - Adult feeding . Stable isotopes - Spiders · Trophic fractionation · Mixing models

\section{Introduction}

In natural streams, aquatic and terrestrial environments are strongly coupled by energy flows in both directions (Polis et al. 1997; Wallace et al. 1997; Nakano et al. 1999; Baxter et al. 2005). In this context, emergence of aquatic insects is an important vector for the flow of aquatic-derived energy into riparian habitats (Jackson and Fisher 1986; Gratton et al. 2008; Nakano and Murakami 2001). A variety of riparian consumers, including birds (Murakami and 
Nakano 2002), lizards (Sabo and Power 2002) and predatory arthropods (Sanzone et al. 2003; Hering and Plachter 1997), have been shown to rely to a certain extent, if not fully (Paetzold et al. 2005), on aquatic prey subsidies.

As predation behaviours differ and predators target different types of prey (Paetzold and Tockner 2005; Collier et al. 2002; Sanzone et al. 2003), the extent of reliance on aquatic insect subsidies is predator-specific. Adult aquatic insects with a terrestrial stage are exposed to riparian predators both at the stream during the transition from aquatic to terrestrial habitat (emergence), and during their stay in the terrestrial habitat often involving inland dispersal (Kovats et al. 1996). Taxon-specific traits related to emergence and dispersal behaviour determine the type of predator to which they are exposed. For instance, caddisflies and stoneflies that emerge by crawling on land (Hynes 1970) are typical prey for nocturnal ground-dwelling predators such as beetles and riparian lycosid spiders (Paetzold and Tockner 2005). Many chironomids and mayflies (e.g. Baetidae), in contrast, emerge to winged adult stages directly from the water surface (Hynes 1970). These taxa appear to be less vulnerable to most grounddwelling predators, while being more susceptible to predation by web-building spiders (Chan et al. 2009; Nentwig 1980). Specifics of dispersal behaviour (e.g. choice of dwelling habitat, swarming behaviour) and flight capacity determine vulnerability of terrestrial adults to predation after emergence from the aquatic habitat.

Stable carbon and nitrogen isotope ratios are widely applied to provide time-integrated information on energy flow through food webs (Cabana and Rasmussen 1996; Finlay 2001). Ratios of stable isotopes change (often on the time scale of days; Ostrom et al. 1997; Kato et al. 2004) between energy source and consumer due to differential digestion or trophic fractionation during assimilation and metabolic processes (McCutchan et al. 2003). Given distinguishable types of basal resources available (e.g. aquatic- and terrestrial-derived carbon), paths of resources can be tracked through the food web with the help of $\delta^{13} \mathrm{C}$, which has low fractionation rates (widely assumed mean value $=0.4 \%$; Post 2002; Vander Zanden and Rasmussen 1999). In contrast, nitrogen stable isotope ratios accumulating on average $3.4 \%$ from one trophic level to another in the food chain are often used to determine the trophic position of consumers (Post 2002).

In this study, we applied stable isotope methodology to investigate cross-boundary trophic links between aquaticderived prey and riparian arthropod predators.

Our primary goal was to test whether terrestrial adults of aquatic insects subsidized different types of riparian arthropod predators feeding in close proximity to highelevation headwater streams (where highest availability of aquatic prey would be expected) in the western Colorado
Rocky Mountains, USA. We measured natural $\delta^{13} \mathrm{C}$ and $\delta^{15} \mathrm{~N}$ signatures to estimate the relative contribution of potential terrestrial and aquatic prey types to the diet of ground-dwelling and web-building riparian predatory arthropods and also estimated activity-density of the latter in two streams. The benthos of Marmot Creek was composed of mostly mayflies (Ephemeroptera), stoneflies (Plecoptera) and midges (Chironomidae). Whiterock Creek was dominated by midges (Chironomidae) and caddisflies (Trichoptera), but also contained larvae of mayflies and stoneflies (Peckarsky B.L., unpublished data).

The key question we aimed to address was: do the isotopic signatures of riparian predators with different hunting strategies show evidence of different extent of reliance on aquatic and terrestrial subsidies from either stream? Furthermore, two post hoc questions emerged after the first year of sampling and early data analysis. First, after initially focusing on isotopic signatures of larval stages of aquatic insects as in many other studies on trophic subsidies (Collier et al. 2002; Paetzold et al. 2005; Walters et al. 2008), we asked: do the isotopic signatures of terrestrial adults of aquatic insects shift with respect to larval signatures and can they still be distinguished from those of prey with exclusively terrestrial life cycles? Second, to estimate reliability of isotope-based conclusions, we tested the extent to which assumptions on trophic fractionation rates affect the estimates of prey contribution to predator diet.

\section{Methods}

\section{Study area}

The study was conducted in 2009-2010 in two west-facing headwater streams, Marmot Creek and Whiterock Creek, draining the East River catchment on the western slope of the Rocky Mountains in Gunnison County, Colorado, USA (latitude $38^{\circ} 959^{\prime} \mathrm{N}$, longitude $106^{\circ} 989^{\prime} \mathrm{W}$ ). The riparian zones of both streams lack gravel bars and are covered with dense willows, and Marmot Creek also has some conifers growing along the edges of the stream channel. Although the streams were similar in size and discharge, they differed in elevation, channel gradient, nutrient availability and geomorphological stability (Online Source 1, Table S1), which was reflected in differences in the abundance and composition of benthic communities. Dominant primary producers in Marmot Creek were diatoms that covered $93 \%$ of the rocks and gravel, whereas aquatic moss was more abundant in Whiterock Creek (27\% moss cover vs. $50 \%$ cover by diatoms). Mean overall aquatic insect density was 2,569.7 \pm SE $443.7 \mathrm{~N} / \mathrm{m}^{2}$ in Marmot Creek and 5,096.2 $\pm \mathrm{SE} 2,093.2 \mathrm{~N} / \mathrm{m}^{2}$ in Whiterock Creek, the difference being primarily due to a high density 
of chironomids in Whiterock Creek. The zoobenthic communities of the two streams were composed of mayflies, stoneflies, caddisflies and dipterans (primarily Chironomidae), but the relative proportions of those taxa differed between the two streams (Marmot Creek: $37.8 \%$ dipterans, $26.2 \%$ mayflies, $19.5 \%$ stoneflies and $3.8 \%$ caddisflies; Whiterock Creek: $68.1 \%$ dipterans, $10.8 \%$ caddisflies, $6.0 \%$ stoneflies, and $3.2 \%$ mayflies; Peckarsky, B. L., unpublished data 2006).

\section{Macroinvertebrate sampling}

We sampled riparian predators and aquatic and terrestrial prey on 19 June and 16 July 2009 both to capture a broader range of the phenology of predators and to avoid missing available prey species and thereby compromise the resolution of the isotopic analyses. We used pitfall traps, a method that captures soil fauna in proportion to their activity (Nentwig 1982), for the collection of ground-dwelling predators and as a by-catch, of terrestrial prey as well as the terrestrial stages of aquatic prey. Traps (transparent plastic cups, depth $=7 \mathrm{~cm}$, top diameter $=9 \mathrm{~cm}, \quad$ bottom $\quad$ diameter $=5.3 \mathrm{~cm}$ ) were installed for $24 \mathrm{~h}$ in the riparian zone along $50-\mathrm{m}$ reaches immediately adjacent to each stream and divided into ten $5 \mathrm{~m}$-sections (strata). The traps were filled with soapy water and distributed within the reach on both sides of the stream at random locations: one trap within each $5 \mathrm{~m}$ of the study reach $(\mathrm{N}=10$; stratified random design). Main samples of terrestrial invertebrates (herbivore prey and predators) and terrestrial adults of aquatic insects for isotope analyses were collected with a sweep net from air and vegetation within $5 \mathrm{~m}$ of the stream bank. Benthic invertebrate samples were collected with a D-net and common taxa were identified and preserved for isotope analysis. We used Ubick et al. (2005) for identification of spiders, and Merritt et al. (2008), Baumann et al. (1977), Peckarsky et al. (1985) to determine aquatic insect larvae and adults.

To compare potential differences in isotopic signatures between larvae and adults, additional samples of prey were collected in July 2010. We collected larvae and adults of three taxonomically distant aquatic species that differ in their adult feeding biology: Baetis bicaudatus (Ephemeroptera, Baetidae), Allomyia gnathos (Trichoptera, Apataniidae) and Zapada haysi (Plecoptera, Nemouridae). Adult mayflies have atrophied mouthparts and do not feed in the terrestrial environment (Brittain 1982), while terrestrial feeding has been reported for adults of some caddisfly, dipteran and stonefly taxa (e.g. Petersson and Hasselrot 1994; Winterbourn 2005; Hynes 1942). As the diversity of larval feeding types in chironomids is very high (Pinder 1986) and analyzing individual species was beyond the scope of this study, only adults of this family were collected.

Hereafter, we use the term "aquatic prey" to refer to taxa with aquatic larval and terrestrial adult stages. When describing isotopic signatures, the term "distinctly aquatic" will be used to refer to "aquatic prey" (as defined above) with isotopic signatures that do not change between the aquatic larval and terrestrial adult stages, and therefore, are distinctly different from terrestrial prey. We will use the term "aquatic-derived" to refer to taxa of "aquatic prey" whose isotopic signatures change from larvae to adult stages, with adult signatures indistinguishable from that of terrestrial prey. "Terrestrial prey" will be used for prey with entirely terrestrial life cycles.

\section{Statistical analysis}

We conducted a two-way analysis of variance (ANOVA) with "stream $\times$ time" interaction to test the differences in abundance of riparian predators in pitfalls between streams and sampling occasions. We used R Version 2.11.1 (R Core Team 2012) for all analyses. ANOVA assumptions were tested with diagnostic graphs. The abundance of lycosid spiders was box-cox transformed to meet the assumptions of ANOVA.

\section{Isotope analysis}

All samples were frozen as soon as possible after sampling, and then oven-dried for $48 \mathrm{~h}$ at $40{ }^{\circ} \mathrm{C}$. Several individuals (10-15 for smaller species, at least 3 for larger species, except Megarcys signata (Plecoptera) with 1 individual per sample) were sampled per taxon to achieve a mean isotope distribution for each species after homogenization. Homogenized samples of $0.2-0.7 \mathrm{mg}$ were placed into $4 \times 6 \mathrm{~mm}$ cylindrical tin cups and weighed to a precision of $0.001 \mathrm{mg}$ for stable isotope analysis. Nitrogen and carbon isotope composition were determined simultaneously using a ThermoFisher Flash-EA 1112 coupled with a Conflo IV interface to a ThermoFisher Delta V isotope ratio mass spectrometer (IRMS). Samples were combusted in the presence of $\mathrm{O}_{2}$ in an oxidation column at $1,030{ }^{\circ} \mathrm{C}$. Combustion gases were passed through a reduction column $\left(650{ }^{\circ} \mathrm{C}\right.$ ), and the produced $\mathrm{N}_{2}$ and $\mathrm{CO}_{2}$ gases were separated chromatographically and transferred to the IRMS via an open split for on-line isotope measurements. Isotope ratios are reported in the conventional $\delta$-notation with respect to atmospheric $\mathrm{N}_{2}$ (air) and V-PDB (Vienna Pee Dee Belemnite) standards, respectively. The methods were calibrated with IAEA-N1 $\left(\delta^{15} \mathrm{~N}=0.45\right), \quad$ IAEA-N2 $\left(\delta^{15} \mathrm{~N}=+20.41\right)$ and IAEA N3 $\left(\delta^{15} \mathrm{~N}=+4.72\right)$ reference materials for nitrogen, and NBS22 $\left(\delta^{13} \mathrm{C}=-30.03\right)$ and IAEA CH-6 $\left(\delta^{13} \mathrm{C}=-10.46\right)$ for carbon. Three 
measurements $(\mathrm{N}=3)$ were conducted per each sample, their reproducibility being $<0.15 \%$ for both $\delta^{13} \mathrm{C}$ and $\delta^{15} \mathrm{~N}$.

Diets of three predators potentially feeding on aquatic prey from Whiterock Creek were analyzed with a Bayesian stable isotope mixing model SIAR v 4.2 (function 'siarsolomcmcv4', $\mathrm{N}$ iterations $=500,000$; Parnell et al. 2010) in R 2.11.1 ( $\mathrm{R}$ Core Team 2012). Bayesian inference incorporates several sources of variability within the model, while allowing for multiple dietary sources and generating potential dietary solutions as true probability distributions (Parnell et al. 2010). The analysis was run on three spider taxa that differ in their hunting strategies and isotopic signatures: Linyphiidae (web-building), Lycosidae (wandering), Liocranidae (wandering).

Using two tracers $\left(\delta^{13} \mathrm{C}\right.$ and $\left.\delta^{15} \mathrm{~N}\right)$, we evaluated the contributions of four prey types with distinctly different isotopic signatures: (1) adult Baetis bicaudatus and Allomyia gnathos (pooled into a mean value due to high similarity of their signatures), (2) adult chironomids, (3) "recently-emerged" adult Zapada haysi (June sample 2009) and (4) terrestrial prey (mean value over the two sampling dates and two phytophagous taxa). The choice of sources for the mixing model analysis included all prey types in our study sites whose contributions to predator diets could be distinguished based on isotopes.

Based on existing knowledge of riparian arthropod feeding (e.g. Paetzold et al. 2005), we expected the spiders to be direct consumers of sampled prey types. As trophic fractionation rates can vary considerably for both isotopes, we ran the model under different assumptions of fractionation and tested combinations of fractionation rates within reported ranges $0.4-3.5$ for $\mathrm{C}^{13}(-1.5,0.5,2.5)$ and $1.5-5.5$ for $\mathrm{N}^{15}(1.5,3.5,5.5)$ (Post 2002; Minagawa and Wada 1984) allowing for standard deviation of \pm 1 .

In this way, we could evaluate the sensitivity of mixingmodel-based estimates of resource partitioning to assumptions on trophic fractionation.

\section{Results}

Riparian predator community

In total, 10 web-weaving and ground-dwelling predator taxa were collected with sweep nets and pitfall traps (Table 1). Based on both sampling methods, some differences in composition of riparian arthropod predator community were found between the two streams. Three spider families were only found at Whiterock Creek (Tetragnathidae, Liocranidae and Theridiidae), whereas myriapods and Thomisidae were collected only at Marmot Creek. All collected riparian predator taxa were included in the isotope analysis.
Riparian predators represented on average $41 \%$ (Marmot) to $51 \%$ (Whiterock) of pitfall trap catches. The remaining pitfall trap catches were both terrestrial and aquatic (primarily dipteran) non-predatory arthropods (Online Source 1: Tables S2 and S3). Ants (Formicoidea) and lycosid and linyphiid spiders were most abundant among predators caught with pitfall traps at both streams (Fig. 1). Mean predator abundance per pitfall trap (per $24 \mathrm{~h}$ ) was significantly different: $5.16 \pm$ SE 0.91 at Whiterock Creek versus $2.95 \pm$ SE 0.52 at Marmot Creek (ANOVA: $F=4.73, p=0.04$ ), which indicates a higher activity-abundance of ground-dwelling predators at Whiterock Creek. This result was primarily attributed to lycosid spiders, which were significantly more abundant in pitfall traps adjacent to Whiterock than Marmot during both collection times (ANOVA: $F=18.22, p=0.0001$, Fig. 1 ). While there was no significant time effect, a significant stream $\times$ time interaction was detected for the remaining ground-dwelling predators (non-lycosids) caught in pitfall traps, mostly due to Formicoidae, which increased at Marmot Creek and decreased at Whiterock Creek between June and July (ANOVA: $F=4.23, p=0.05$; Fig. 1 ).

Isotope analysis based on aquatic larvae

In both streams, $\delta^{13} \mathrm{C}$ values differed strongly between the terrestrial prey and larvae of aquatic prey (on average by $7.07 \%$ in Marmot Creek and $8.75 \%$ in Whiterock Creek), suggesting a clear separation of those prey sources in carbon signatures (Fig. 2). In both Marmot and Whiterock Creeks, $\delta^{13} \mathrm{C}$ values of all riparian predators fell within the ranges detected for terrestrial prey and showed little variation among predator taxa (Fig. 2a, b) and sampling dates (for full list of isotopic values see Online Source 1: Tables S4 and S5).

Nitrogen isotope signatures of all aquatic larvae sampled within each stream were generally elevated compared to those of terrestrial prey (Fig. 2a, b). In Marmot Creek, $\delta^{15} \mathrm{~N}$ values of riparian predators were on average $0.22 \%$ lower than those of aquatic larvae (both predators and grazers), but were $3.61 \%$ higher than those of terrestrial prey (Fig. 2a). Interestingly, in Whiterock Creek, riparian predator nitrogen signatures were all higher than both aquatic larvae (predators: Rhyacophila, grazers: Neothrema, Allomyia and Baetis, and detritus shredders: Zapada) and terrestrial prey (Fig. 2b), and the gap in $\delta^{15} \mathrm{~N}$ between terrestrial prey and riparian predators was distinctly wider than in Marmot (on average $7.78 \%$ in Whiterock; Fig. 2). Note that $\delta^{15} \mathrm{~N}$ values of both terrestrial and aquatic prey types in Whiterock Creek were substantially lower than those in Marmot Creek. This result is consistent with previously observed differences in nitrogen signatures of primary producers and detritus, both of which were lower 
Table 1 Overview of aquatic (larval) and riparian invertebrates included in the isotope analysis

\begin{tabular}{|c|c|c|c|c|c|c|}
\hline \multicolumn{4}{|c|}{ Presence of taxon } & \multirow[t]{3}{*}{ Sampling method } & \multirow[t]{3}{*}{ Taxon } & \multirow[t]{3}{*}{ Comments } \\
\hline \multicolumn{2}{|c|}{ Marmot } & \multicolumn{2}{|c|}{ Whiterock } & & & \\
\hline June & July & June & July & & & \\
\hline \multicolumn{7}{|c|}{ Riparian predators } \\
\hline \multirow[t]{6}{*}{+} & + & + & + & Pitfall & Linyphiidae & Araneae, sheet-web weaving spiders \\
\hline & + & $(+)$ & + & Pitfall & Dictynidae & $\begin{array}{l}\text { Araneae, spiders which build irregular webs close } \\
\text { to or directly on the ground }\end{array}$ \\
\hline & + & & & & Thomisidae & Araneae, sit-and-wait spiders (on vegetation) \\
\hline & & & + & Sweep net & Tetragnathidae & Araneae, horizontal orb-weaving spiders \\
\hline & & & + & Sweep net & Theridiidae & Araneae, spiders which build tangle space webs \\
\hline & & + & + & Pitfall/sweep net & Liocranidae & Araneae, wandering spiders \\
\hline+ & & & + & Pitfall/sweep net & Gnaphosidae & $\begin{array}{l}\text { Araneae, wandering or sit-and-wait spiders } \\
\text { (on the ground) }\end{array}$ \\
\hline+ & + & + & + & Pitfall & Lycosidae & Araneae, wandering and hunting spiders \\
\hline+ & + & + & + & Pitfall & Formicoidae (2 taxa) & Hymenoptera, wandering omnivores \\
\hline+ & + & & & Pitfall & Myriapoda & Wandering predator \\
\hline \multicolumn{7}{|c|}{ Aquatic grazers } \\
\hline+ & + & & + & Kick sampling & Baetis bicaudatus (Dodds) & Ephemeroptera, grazer \\
\hline \multirow[t]{3}{*}{+} & + & & & - & Cinygmula spp. & Ephemeroptera, grazer \\
\hline & & + & + & - & Allomyia gnathos (Ross) & Trichoptera, grazer \\
\hline & & + & & - & Zapada haysi (Ricker) & Plecoptera, shredder \\
\hline \multirow[t]{4}{*}{+} & + & & & - & Megarcys signata (Hagen) & Plecoptera, predator \\
\hline & & + & + & - & Neothremma alicia (Dodds and Hisaw) & Trichoptera, grazer \\
\hline & & & + & - & Rhyacophila alberta (Banks) & Trichoptera, predator \\
\hline & + & & & - & Arctopsyche grandis (Banks) & Trichoptera, mixed diet \\
\hline \multicolumn{7}{|c|}{ Terrestrial prey } \\
\hline+ & + & & & Sweep net & Heteroptera & Hemiptera, phytophag \\
\hline \multirow[t]{3}{*}{+} & + & + & + & - & Phylloidea & Sternorrhyncha, phytophag \\
\hline & + & & & - & Aphidae & Hemiptera, phytophag \\
\hline & & + & + & - & Auchenorrhyncha & Hemiptera, phytophag \\
\hline
\end{tabular}

In parentheses, taxa that were detected on the sampling occasion but could not be analyzed due to small sample size. Spider typology taken from Collier et al. (2002), Wise (1993), Sanzone et al. (2003)

in Whiterock Creek than Marmot Creek (Moslemi, J. M., unpublished data). Nitrogen signatures shifted little between the two dates in most predator and prey groups sampled on both occasions, the only exceptions being Liocranidae in Whiterock Creek and Cinygmula spp. and Baetis bicaudatus in Marmot Creek, which were more depleted in ${ }^{15} \mathrm{~N}$ in July (Fig. 2). Notably however, we did find evidence of variability in isotopic signatures between larval stages of the same prey sampled in different seasons or years (see Baetis bicaudatus; Fig. 2, Table S6).

Isotope analysis: shifts between larval and adult isotopic signatures

In all tested species of aquatic insects, we observed some variation between the life stages with respect to $\delta^{13} \mathrm{C}$ and $\delta^{15} \mathrm{~N}$ enrichment (Fig. 3; Online Source 1: Table S6). For the two species of aquatic algal grazers Baetis bicaudatus mayflies and Allomyia gnathos caddisflies, shifts in isotopic signatures between larvae and adults were rather moderate, and their adult carbon and nitrogen isotope signatures remained distinctly different from those of terrestrial prey (Fig. 3b). In contrast, both $\delta^{13} \mathrm{C}$ and $\delta^{15} \mathrm{~N}$ of the detritus shredder Zapada haysi changed considerably between larval and adult life stages with adults becoming more similar to terrestrial prey (Fig. 3a, b). This change was progressive-with the highest shift of isotopic signatures towards "terrestrial" in samples taken later in July 2009 (Fig. 3b) and 2010 (Table S6). The adult signature of Zapada haysi fell within the range of terrestrial prey for both $\mathrm{C}$ and $\mathrm{N}$ isotopes in Marmot and was more depleted in carbon by only about $1 \%$ than terrestrial prey in 


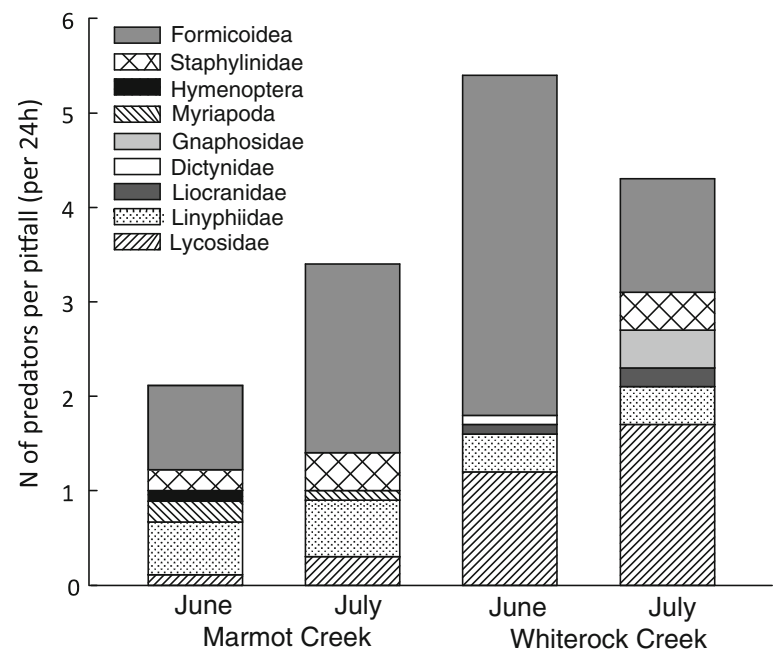

Fig. 1 Mean abundance of riparian predatory taxa per pitfall per $24 \mathrm{~h}$

Whiterock (Fig. 3). Notably, while the $\delta^{13} \mathrm{C}$ of "aquaticderived" adults of Chironomidae (Diptera) in Whiterock was indistinguishable from that of terrestrial prey, their $\delta{ }^{15} \mathrm{~N}$ remained similar to aquatic taxa: elevated in chironomids by $2.99 \%$ compared to terrestrial prey (Fig. 3b).

Mixing model analysis

Based on the results described in the previous sections, we focused the mixing model analysis on the adult stages of aquatic prey that had isotopic signatures distinct from those of terrestrial prey and for which we had the most complete data. Therefore, we conducted mixing model analysis on samples of adult grazers (Baetis and Allomyia), early adult Zapada (June samples), chironomids and terrestrial prey from Whiterock Creek. Note that contribution of "cryptic prey", such as late Zapada adults, could not be distinguished from that of terrestrial prey.

Within the tested combinations of different assumptions on ${ }^{13} \mathrm{C}$ and ${ }^{15} \mathrm{~N}$ fractionation levels, the uncertainty of estimates generally increased with higher assumed fractionation rates of ${ }^{15} \mathrm{~N}$ (Tables 2, 3, 4, 5; Fig. 4). Adult chironomids appeared to be the most consistent component of the diet of all three predator taxa: confidence intervals for estimates of chironomid contribution never included "zero" (with the exception of Liocranidae in July at fractionation rates 5.5 for ${ }^{15} \mathrm{~N}$ and -1.5 for ${ }^{13} \mathrm{C}$ ). The estimated proportions (95\%-ile estimates) varied dramatically depending on fractionation assumptions (Tables 2, 3, 4, 5), ranging from 2 to $97 \%$ of linyphiid diet, 15-99\% of lycosid diet and 0-99\% of liocranid diet (20-99 \% in June). We found no reliable indication of predation by spiders on early adult Zapada haysi, as estimates for its contribution to diet always included "zero" in the confidence intervals (Tables 2, 3, 4, 5). For
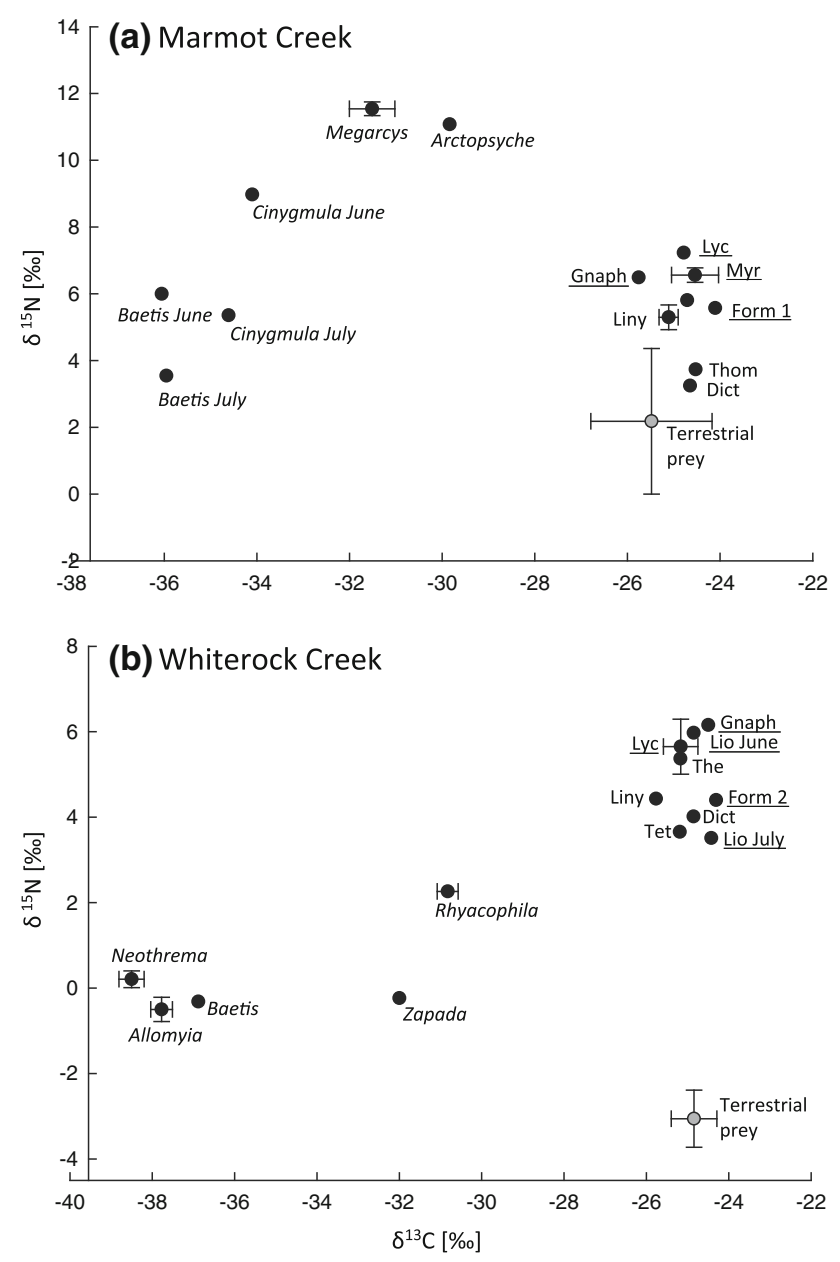

Fig. $2 \delta^{15} \mathrm{~N}$ and $\delta^{13} \mathrm{C}$ of riparian predators and aquatic and terrestrial prey at Marmot Creek (a) and Whiterock Creek (b) in summer 2009. For predator and prey taxa collected on both sampling dates, data are pooled, with the exception of Liocranidae, Baetis bicaudatus and Cinygmula spp. whose nitrogen isotopic signature differed strongly between June and July. Larval isotopic signatures are shown for aquatic insects. Letter codes indicate different riparian predator taxa: Lycosidae (Lyc), Thomisidae (Thom), Dictionidae (Dict), Linyphiidae (Liny), Liocranidae (Lio), Gnaphosidae (Gnaph), Theridiidae (The), Tetragnathidae (Tet), Formicoidae (Form), Myriapoda (Myr). Labels for ground-dwelling predators are underlined, the rest of riparian predators are web-weaving spiders. Isotopic values are not corrected for fractionation. Error bars show standard deviation. Points with no error bars had standard deviations smaller than the size of the point. Please note different scales of the Y-axes for the two streams (a and b)

terrestrial prey and adults of aquatic grazers (Baetis bicaudatus and Allomyia gnathos), the evidence for contribution to diet strongly depended on fractionation assumptions. Terrestrial prey resulted as part of spider diet (linyphiids and liocranids in July) at high fractionation rates assumed for ${ }^{15} \mathrm{~N}(5.5 \pm 1)$, whereas for the aquatic grazer adults it was the case, when high fractionation rates for ${ }^{13} \mathrm{C}$ were assumed $(3.5 \pm 1)$ (linyphiids, lycosids and liocranids in June). 

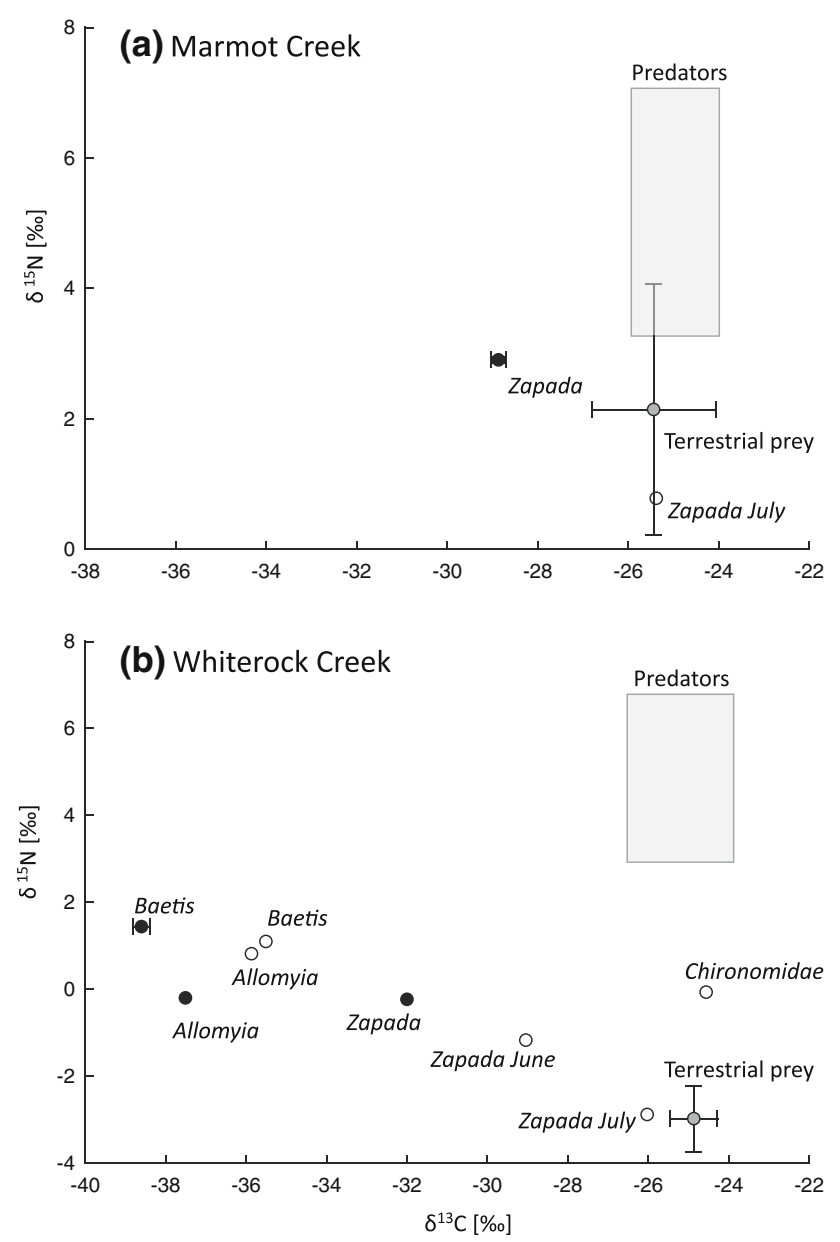

Fig. 3 Comparison of the isotope composition between aquatic larvae and their terrestrial adult stages sampled in Marmot Creek (a) and Whiterock Creek (b). Filled black circles indicate larvae, white circles-adults, grey circles-terrestrial prey. Grey rectangles represent the range of values for riparian predators measured in 2009. Error bars show standard deviation. Points with no error bars had standard deviations smaller than the size of the point. In Whiterock all stages were collected in 2010 for Baetis and 2009 for Zapada, Allomyia and chironomids. Zapada larvae in Marmot were collected in 2010, adults in 2009. All reported larvae but Zapada in Whiterock (June) were collected in July. Isotopic values are not corrected for fractionation

Overall, these analyses demonstrate that diet composition scenarios for individual spider taxa varied considerably depending on the fractionation assumptions, ranging from strongly chironomid-dominated to a highly mixed diet with eventual contributions of aquatic grazer species and terrestrial prey.

\section{Discussion}

Results of the isotope analysis would suggest that the diet of riparian arthropod predators studied in two high-elevation streams was not strongly dependent on the aquatic food web, if such analyses were based solely on comparisons of predators to the larval ${ }^{13} \mathrm{C}$ signatures of aquatic insects. However, observed similarity of adult isotopic signatures of some aquatic taxa (e.g., chironomids and the stonefly Zapada haysi) to terrestrial prey suggests that adults of some of the aquatic-derived prey might become "isotopically cryptic" in the terrestrial environment and therefore remain undetected in the diet of riparian predators. Moreover, the demonstrated sensitivity of mixing models to assumed fractionation rates suggests that investigators should exercise even further caution when drawing conclusions over trophic links based on isotopic data.

Aquatic prey in the diets of different riparian predator taxa

The activity-abundance of lycosid spiders, cursorial predators which in other studies have been shown to opportunistically feed on adults of aquatic insects and respond to emergence pulses with elevated densities (Power et al. 2004; Paetzold et al. 2006), was significantly higher adjacent to Whiterock Creek than Marmot Creek. Moreover, Tetragnathidae, typical riparian specialists (Power et al. 2004), as well as some other spider taxa, were only found at Whiterock Creek, suggesting a greater potential for those predators to feed on adults of aquatic prey at this stream compared to Marmot Creek.

While isotope analysis based only on larval carbon signatures of aquatic prey could suggest that riparian predators in both streams feed exclusively on terrestrial prey, our comparison of adult and larval isotopic signatures as well as mixing model analysis based on both $\delta^{13} \mathrm{C}$ and $\delta^{15} \mathrm{~N}$ indicate a more complex picture. The presence of aquatic species that change their isotopic signature between larval and adult stages towards that of terrestrial prey shows that some "aquatic-derived" prey become "isotopically cryptic" and cannot be distinguished from terrestrial prey with a stable isotope approach. For example, while we can be confident concluding that adults of "distinctly aquatic" prey such as Baetis and Allomyia are or are not included in riparian predator diets, predation on late stages of adult nemourids (Zapada) cannot be distinguished from predation on terrestrial prey species.

The "cryptic prey" problem may also explain the wide gap in nitrogen signatures between riparian predators and terrestrial prey in Whiterock, suggesting that some aquatic prey with intermediate values of $\delta^{15} \mathrm{~N}$ must be incorporated into the diet of riparian predators, even though predator carbon signatures lie in the range of terrestrial prey. In fact, our mixing model analysis suggested that at least one aquatic-derived taxon (chironomids) clearly contributes to the spider diets. Their small size and weak flight capacity make adult chironomids a typical target prey for many 
Table 2 Estimates for contribution of single prey types to the diet of Linyphiidae resulting from mixing model analysis under different assumptions on fractionation

\begin{tabular}{|c|c|c|c|c|c|c|c|c|c|c|c|c|c|}
\hline \multicolumn{2}{|c|}{ Fractionation assumed } & \multicolumn{3}{|c|}{ Chironomidae } & \multicolumn{3}{|c|}{ Zapada June } & \multicolumn{3}{|c|}{ Terrestrial } & \multicolumn{3}{|c|}{ Baetis/Allomyia } \\
\hline $\mathrm{N}$ & $\mathrm{C}$ & LCI & Mean & UCI & LCI & Mean & UCI & LCI & Mean & UCI & LCI & Mean & UCI \\
\hline 1.5 & -1.5 & 0.77 & 0.87 & 0.97 & 0.00 & 0.04 & 0.12 & 0.00 & 0.04 & 0.12 & 0.00 & 0.04 & 0.11 \\
\hline 1.5 & 0.5 & 0.66 & 0.80 & 0.94 & 0.00 & 0.06 & 0.17 & 0.00 & 0.04 & 0.10 & 0.00 & 0.04 & 0.22 \\
\hline 1.5 & 2.5 & 0.44 & 0.61 & 0.79 & 0.00 & 0.06 & 0.16 & 0.00 & 0.03 & 0.09 & 0.13 & 0.30 & 0.46 \\
\hline 3.5 & -1.5 & 0.56 & 0.77 & 0.96 & 0.00 & 0.07 & 0.19 & 0.00 & 0.12 & 0.32 & 0.00 & 0.04 & 0.11 \\
\hline 3.5 & 0.5 & 0.36 & 0.62 & 0.86 & 0.00 & 0.16 & 0.42 & 0.00 & 0.11 & 0.33 & 0.00 & 0.11 & 0.22 \\
\hline 3.5 & 2.5 & 0.20 & 0.43 & 0.66 & 0.00 & 0.19 & 0.46 & 0.00 & 0.11 & 0.30 & 0.11 & 0.27 & 0.43 \\
\hline 5.5 & -1.5 & 0.15 & 0.49 & 0.84 & 0.00 & 0.09 & 0.22 & 0.02 & 0.38 & 0.70 & 0.00 & 0.03 & 0.09 \\
\hline 5.5 & 0.5 & 0.10 & 0.37 & 0.63 & 0.00 & 0.23 & 0.44 & 0.04 & 0.32 & 0.57 & 0.00 & 0.08 & 0.19 \\
\hline 5.5 & 2.5 & 0.02 & 0.25 & 0.44 & 0.00 & 0.26 & 0.50 & $\mathbf{0 . 0 3}$ & 0.27 & 0.47 & 0.07 & 0.22 & 0.36 \\
\hline
\end{tabular}

Confidence intervals in bold did not include "zero"

UCI upper confidence interval (95\%), LCI lower confidence interval (95\%)

Table 3 Estimates for contribution of single prey types to the diet of Lycosidae resulting from mixing model analysis under different assumptions on fractionation

\begin{tabular}{|c|c|c|c|c|c|c|c|c|c|c|c|c|c|}
\hline \multicolumn{2}{|c|}{ Fractionation assumed } & \multicolumn{3}{|c|}{ Chironomidae } & \multicolumn{3}{|c|}{ Zapada June } & \multicolumn{3}{|c|}{ Terrestrial } & \multicolumn{3}{|c|}{ Baetis/Allomyia } \\
\hline $\mathrm{N}$ & $\mathrm{C}$ & LCI & Mean & UCI & LCI & Mean & UCI & LCI & Mean & UCI & LCI & Mean & UCI \\
\hline 1.5 & -1.5 & 0.84 & 0.91 & 0.99 & 0.00 & 0.03 & 0.08 & 0.00 & 0.03 & 0.08 & 0.00 & 0.03 & 0.08 \\
\hline 1.5 & 0.5 & 0.77 & 0.87 & 0.97 & 0.00 & 0.04 & 0.11 & 0.00 & 0.03 & 0.08 & 0.00 & 0.06 & 0.15 \\
\hline 1.5 & 2.5 & 0.61 & 0.76 & 0.94 & 0.00 & 0.04 & 0.10 & 0.00 & 0.02 & 0.06 & 0.01 & 0.18 & 0.33 \\
\hline 3.5 & -1.5 & 0.75 & 0.86 & 0.97 & 0.00 & 0.05 & 0.13 & 0.00 & 0.06 & 0.15 & 0.00 & 0.03 & 0.09 \\
\hline 3.5 & 0.5 & 0.63 & 0.78 & 0.94 & 0.00 & 0.08 & 0.22 & 0.00 & 0.05 & 0.15 & 0.00 & 0.08 & 0.19 \\
\hline 3.5 & 2.5 & 0.43 & 0.62 & 0.81 & 0.00 & 0.09 & 0.30 & 0.00 & 0.05 & 0.13 & 0.07 & 0.24 & 0.39 \\
\hline 5.5 & -1.5 & 0.39 & 0.71 & 0.96 & 0.00 & 0.06 & 0.17 & 0.00 & 0.20 & 0.53 & 0.00 & 0.03 & 0.08 \\
\hline 5.5 & 0.5 & 0.28 & 0.56 & 0.85 & 0.00 & 0.16 & 0.38 & 0.00 & 0.21 & 0.46 & 0.00 & 0.07 & 0.17 \\
\hline 5.5 & 2.5 & 0.15 & 0.39 & 0.64 & 0.00 & 0.23 & 0.48 & 0.00 & 0.18 & 0.39 & 0.04 & 0.20 & 0.35 \\
\hline
\end{tabular}

Confidence intervals in bold did not include "zero"

UCI upper confidence interval (95\%), LCI lower confidence interval (95\%)

Table 4 Estimates for contribution of single prey types to the diet of Liocranidae (June) resulting from mixing model analysis under different assumptions on fractionation

\begin{tabular}{|c|c|c|c|c|c|c|c|c|c|c|c|c|c|}
\hline \multicolumn{2}{|c|}{ Fractionation assumed } & \multicolumn{3}{|c|}{ Chironomidae } & \multicolumn{3}{|c|}{ Zapada June } & \multicolumn{3}{|c|}{ Terrestrial } & \multicolumn{3}{|c|}{ Baetis/Allomyia } \\
\hline $\mathrm{N}$ & C & LCI & Mean & UCI & LCI & Mean & UCI & LCI & Mean & UCI & LCI & Mean & UCI \\
\hline 1.5 & -1.5 & 0.85 & 0.92 & 0.99 & 0.00 & 0.03 & 0.07 & 0.00 & 0.02 & 0.07 & 0.00 & 0.02 & 0.07 \\
\hline 1.5 & 0.5 & 0.80 & 0.89 & 0.98 & 0.00 & 0.03 & 0.09 & 0.00 & 0.02 & 0.07 & 0.00 & 0.05 & 0.12 \\
\hline 1.5 & 2.5 & 0.67 & 0.81 & 0.96 & 0.00 & 0.03 & 0.09 & 0.00 & 0.02 & 0.06 & 0.00 & 0.13 & 0.26 \\
\hline 3.5 & -1.5 & 0.78 & 0.88 & 0.98 & 0.00 & 0.04 & 0.11 & 0.00 & 0.05 & 0.13 & 0.00 & 0.03 & 0.08 \\
\hline 3.5 & 0.5 & 0.68 & 0.82 & 0.95 & 0.00 & 0.06 & 0.18 & 0.00 & 0.05 & 0.14 & 0.00 & 0.07 & 0.16 \\
\hline 3.5 & 2.5 & 0.51 & 0.68 & 0.86 & 0.00 & 0.08 & 0.22 & 0.00 & 0.04 & 0.11 & 0.04 & 0.21 & 0.35 \\
\hline 5.5 & -1.5 & 0.53 & 0.78 & 0.98 & 0.00 & 0.05 & 0.15 & 0.00 & 0.13 & 0.40 & 0.00 & 0.03 & 0.08 \\
\hline 5.5 & 0.5 & 0.36 & 0.64 & 0.90 & 0.00 & 0.13 & 0.32 & 0.00 & 0.17 & 0.43 & 0.00 & 0.07 & 0.15 \\
\hline 5.5 & 2.5 & 0.20 & 0.45 & 0.70 & 0.00 & 0.22 & 0.49 & 0.00 & 0.15 & 0.37 & 0.02 & 0.18 & 0.32 \\
\hline
\end{tabular}

Confidence intervals in bold did not include "zero"

UCI upper confidence interval (95\%), LCI lower confidence interval (95\%) 
Table 5 Estimates for contribution of single prey types to the diet of Liocranidae (July) resulting from mixing model analysis under different assumptions on fractionation

\begin{tabular}{|c|c|c|c|c|c|c|c|c|c|c|c|c|c|}
\hline \multicolumn{2}{|c|}{ Fractionation assumed } & \multicolumn{3}{|c|}{ Chironomidae } & \multicolumn{3}{|c|}{ Zapada June } & \multicolumn{3}{|c|}{ Terrestrial } & \multicolumn{3}{|c|}{ Baetis/Allomyia } \\
\hline $\mathrm{N}$ & $\mathrm{C}$ & LCI & Mean & UCI & LCI & Mean & UCI & LCI & Mean & UCI & LCI & Mean & UCI \\
\hline 1.5 & -1.5 & 0.77 & 0.88 & 0.98 & 0.00 & 0.04 & 0.11 & 0.00 & 0.05 & 0.15 & 0.00 & 0.03 & 0.07 \\
\hline 1.5 & 0.5 & 0.67 & 0.81 & 0.95 & 0.00 & 0.07 & 0.19 & 0.00 & 0.06 & 0.17 & 0.00 & 0.06 & 0.14 \\
\hline 1.5 & 2.5 & 0.49 & 0.68 & 0.87 & 0.00 & 0.10 & 0.31 & 0.00 & 0.05 & 0.15 & 0.01 & 0.17 & $\mathbf{0 . 3 0}$ \\
\hline 3.5 & -1.5 & 0.44 & 0.76 & 0.98 & 0.00 & 0.05 & 0.13 & 0.00 & 0.17 & 0.50 & 0.00 & 0.02 & 0.07 \\
\hline 3.5 & 0.5 & 0.31 & 0.60 & 0.89 & 0.00 & 0.11 & 0.29 & 0.00 & 0.24 & 0.51 & 0.00 & 0.05 & 0.12 \\
\hline 3.5 & 2.5 & 0.17 & 0.42 & 0.70 & 0.00 & 0.23 & 0.48 & 0.00 & 0.21 & 0.42 & 0.00 & 0.13 & 0.26 \\
\hline 5.5 & -1.5 & 0.00 & 0.34 & 0.77 & 0.00 & 0.05 & 0.13 & 0.15 & 0.59 & 0.95 & 0.00 & 0.02 & 0.06 \\
\hline 5.5 & 0.5 & 0.03 & 0.36 & 0.63 & 0.00 & 0.12 & 0.30 & 0.19 & 0.47 & 0.79 & 0.00 & 0.04 & 0.11 \\
\hline 5.5 & 2.5 & 0.01 & 0.24 & 0.45 & 0.00 & 0.27 & 0.50 & 0.13 & 0.39 & 0.65 & 0.00 & 0.10 & 0.22 \\
\hline
\end{tabular}

Confidence intervals in bold did not include "zero"

UCI upper confidence interval (95\%), LCI lower confidence interval (95\%)

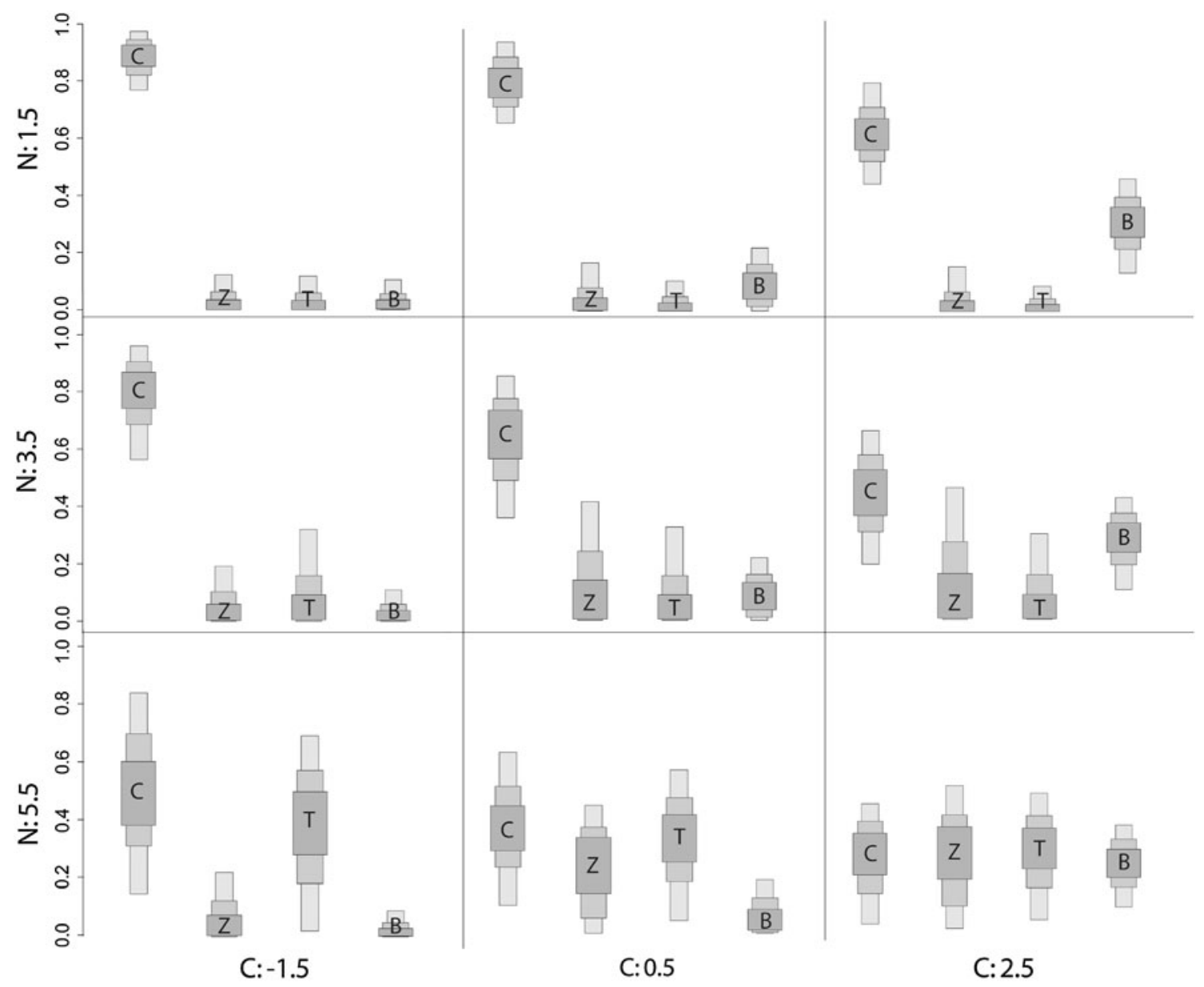

Fig. 4 An example of variation in mixing model estimates (SIAR) driven by different assumptions on fractionation: estimates of the contributions to the diets of Linyphiidae of terrestrial prey (T) and adults of Chironomidae (C), Zapada (Z), and aquatic grazers Baetis and Allomyia (B) collected in July (June for Zapada) 2009. Each plot shows $5,25,75$ and $95 \%$ credibility intervals. X-axis shows tested assumptions for trophic fractionation of ${ }^{13} \mathrm{C}$, y-axis shows assumptions for trophic fractionation of ${ }^{15} \mathrm{~N}$ 
web-weaving riparian spiders (Linyphiidae, Theridiidae and Tetragnathidae; Nentwig 1980). The capture of chironomid adults in pitfall traps further indicates greater habitat overlap with ground-dwelling riparian predators such as lycosid and liocranid spiders thus potentially explaining their increased activity at Whiterock Creek compared to Marmot Creek.

Finding very little or no support for contribution of Baetis bicaudatus and Allomyia gnathii to spider diets was a surprising result, in particular, for mayflies, which are known to emerge in synchronized pulses in the second half of June in the East River Catchment (Peckarsky et al. 2000). We suggest two possible scenarios in which the subsidy of these species may be taking place but has not been detected in this study. First, productivity of other prey types might be comparably much higher and thus the effects of feeding on adults of aquatic grazers too weak to affect the isotopic signature of the predators. Second, adult mayfly swarms in the East River catchment have been observed at great distances away from streams (Peckarsky et al. 2002), as were the locations where mayflies were collected for this study. Thus, mayfly swarming behaviour could result in little habitat overlap with riparian predators.

Isotopic shifts between aquatic and terrestrial life stages: becoming "cryptic aquatic"

We observed differences between the isotopic signatures of terrestrial and aquatic stages of three taxa (Baetis bicaudatus, Allomyia gnathii, Zapada haysi) and partial or complete overlap of the adult signatures with those of purely terrestrial invertebrate prey in two aquatic groups (chironomids, Zapada haysi). Several mechanisms may explain these observed differences. First, adult feeding on terrestrial food sources could cause an isotopic shift during the terrestrial stage. This effect is expected in species with longer-living adult stages such as nemourids. Such changes in isotopic signatures from aquatic to terrestrial stage probably occur progressively over time spent feeding in terrestrial habitat and resulting in signatures that converge towards those of exclusively terrestrial prey species. In fact, adults of many species within the family Nemouridae feed extensively on protein-rich sources: fungi, terrestrial pollen and lichens (Hynes 1942; De Figueroa and SánchezOrtega 2000) in the terrestrial environment, thereby incorporating both terrestrial carbon and nitrogen into their diet. Our observation of a stronger similarity to terrestrial isotopic signatures in both $\mathrm{C}$ and $\mathrm{N}$ in $Z$. haysi adults collected later in summer (July) compared to samples collected in June is consistent with our speculation that the differences in isotopic signatures between larvae and adults of $Z$. haysi reflect a gradual diet-driven shift.
Terrestrial diet may also explain the partial overlap of chironomid isotopic signatures with those of fully terrestrial prey. However, without a comparison of larval and adult signatures of chironomids and knowledge on the turnover rate of their isotopic signature upon food switch from larval to adult stage, we cannot rule out whether the terrestrial carbon signature of chironomids is caused by larval feeding on terrestrial carbon sources in the water (e.g. leaf litter) or due to a later shift of isotopic signature reflecting adult feeding (e.g. on nectar feeding; Burtt et al. 1986; Schlee 1977) on land. The latter would be possible as flowering plants were highly abundant in the riparian zones of both streams already at the June sampling and, moreover, would be a reasonable explanation to the observed similarity with terrestrial prey in carbon but not nitrogen.

A second possible mechanism explaining isotopic shifts from aquatic larvae to the adult stage is the potential for isotope fractionation during metamorphosis and emergence from larval to adult life stages, which is highly probable as metamorphosis involves biochemical and physical processes which might lead to isotopic fractionation (isotopic differences between the source and the product compounds of a chemical transformation; Sulzman 2007). Observed shifts in the isotopic signatures from larvae to adults of Baetis bicaudatus, a mayfly with extremely short-lived and non-feeding adults, offer the best evidence that some metamorphosis-driven shift in the isotopic composition must be taking place.

Furthermore, differences in larval isotopic signatures detected in some of the prey taxa collected on several occasions on different years and/or seasons, suggests that some additional sources of variation might exist that we did not specifically test in this study. Possibilities are seasonal effects such as timing of snow-melt and temperature patterns as well as food-availability during or prior to sampling. Further research is needed to disentangle those additional sources of variation from the potential for changes in diet to explain the observed shifts in isotopic signatures between aquatic larvae and their terrestrial adult stages.

Quantitative evaluation of diet composition: importance of fractionation assumptions

Our sensitivity analysis for the estimates based on mixing model approaches demonstrated clearly the extent to which the results and conclusions of an isotope study depend on the isotope fractionation assumptions underlying the calculations. Extensive evidence shows that trophic fractionation rates can vary considerably (Post 2002) depending on factors such as temperature, ration size, dietary condition of the consumer, and fat and protein content of the energy source (Barnes et al. 2007; 
McCutchan et al. 2003). In spite of this knowledge, many ecological studies applying this method assume mean fractionation rates reported in the literature (Paetzold et al. 2005; Paetzold et al. 2008; Kato et al. 2004; Sepulveda et al. 2012). Our analysis emphasizes that the dependence of mixing model output on fractionation assumptions can be very high, thereby compromising effectiveness of isotope-based studies on trophic linkages when actual trophic fractionation rates are not measured.

\section{Conclusions and implications}

Results of this study suggest that while being a valuable tool for studies of trophic relationships, stable isotope approach must be implemented cautiously, especially when applied to organisms with complex life-cycles. Sampling larval stages of aquatic insects is not uncommon in studies of aquatic subsidies to consumers in the terrestrial environment (Paetzold et al. 2005; Collier et al. 2002; Walters et al. 2008) and is often used for practical reasons because collecting sufficient numbers of adults in the field can be more difficult.

This study underscores the importance of considering processes that might change isotopic signatures of both predators and prey over time, such as metamorphosis and shifts in feeding behaviour. Furthermore, seasonal effects on isotopic signatures (e.g. physiologically stressful periods of drought, cold temperatures or floods) could also play a role of confounding factors and should be explored in further studies. We suggest that for organisms with complex life-cycles, the adult stages should be sampled over their entire flight periods to assess the potential for progressive changes in the isotopic signatures of species with longer-lived adults. To definitively determine the contributions of "isotopically cryptic" prey types to the diet of terrestrial predators, investigators need to apply other methods such as field observations of predation behaviour of different predator types, gut contents analysis or PCR bases methods in cases of extra-oral digestion as in spiders (Gamboa et al. 2012; Greenstone and Shufran 2003).

As we demonstrated in this study, knowledge on isotopic fractionation rates specific to the study system appears crucial for making reliable quantitative assessments of contribution of different prey types to predator diets. Feeding experiments in the field or in the laboratory would be a helpful tool for estimation of trophic fractionation rates (Gannes et al. 1997; Wise et al. 2006).

Finally, general conclusions of earlier isotope-based studies on freshwater insect subsidies to terrestrial predators are not compromised by these results, because in those studies predators show a clear shift towards aquatic signatures (e.g. Paetzold et al. 2005; Kato et al. 2004) and thus the fact of contribution of aquatic subsidies to their diet would not have been overlooked as may happen in the cases as the one presented here. However, our results demonstrate several sources of uncertainty for isotopebased quantitative estimates of diet composition that previously have received little attention and should be taken into account in future studies involving prey species with complex life-cycles.

Acknowledgments We thank Wendy Brown for assistance in the field and laboratory and particularly for spider identification, Steve Horn, Maruxa Alvarez, Angus McIntosh, Marge Penton and Carrie Robbins for help in the field and fruitful discussions on the project, Jen Moslemi for kindly providing her isotope data, Billy Barr and the Rocky Mountain Biological Laboratory for providing support and facilities for this study, anonymous reviewers whose comments helped to improve the manuscript from earlier versions and Jake Vander Zanden and Erika Nilsson for valuable advice when planning the study. This project was partially funded by an Eawag Mobility Grant to M. Alp, the Swiss Federal Department of the Environment, and National Science Foundation Grant no. DEB — 0516035 awarded to B.L. Peckarsky. IGB Fellowship in Freshwater Science supported Maria Alp during preparation of this manuscript.

\section{References}

Barnes C, Sweeting CJ, Jennings S, Barry JT, Polunin NVC (2007) Effect of temperature and ration size on carbon and nitrogen stable isotope trophic fractionation. Funct Ecol 21:356-362

Baumann RW, Gaufin AR, Surdick RF (1977) The stoneflies (Plecoptera) of the Rocky Mountains. Mem Amer Entomol Soc 31:1-208

Baxter CV, Fausch KD, Saunders WC (2005) Tangled webs: reciprocal flows of invertebrate prey link streams and riparian zones. Freshw Biol 50:201-220

Brittain JE (1982) Biology of mayflies. Ann Rev Entomol 27: 119-147

Burtt ET, Perry RJO, McLachlan AJ (1986) Feeding and sexual dimorphism in adult midges (Diptera: Chironomidae). Holarct Ecol 9:27-32

Cabana G, Rasmussen JB (1996) Comparison of aquatic food chains using nitrogen isotopes. Proc Nat Acad Sci 93:10844-10847

Chan EKW, Zhang Y, Dudgeon D (2009) Substrate availability may be more important than aquatic insect abundance in the distribution of riparian orb-web spiders in the tropics. Biotropica 41:196-201

Collier KJ, Bury S, Gibbs M (2002) A stable isotope study of linkages between stream and terrestrial food webs through spider predation. Freshw Biol 47:1651-1659

De Figueroa JMT, Sánchez-Ortega A (2000) Imaginal feeding of twelve nemouroidean stonefly species (Insecta, Plecoptera). Ann Entomol Soc Am 93:251-253

Finlay JC (2001) Stable-carbon-isotope ratios of river biota: implications for energy flow in lotic food webs. Ecology 82: $1052-1064$

Gamboa M, Kimbirauskas RK, Merritt RW, Monaghan MT (2012) A molecular approach to identifying the natural prey of the african creeping water bug Naucoris, a potential reservoir of Mycobacterium ulcerans. J Insect Sci 12:1-10

Gannes LZ, O’Brien DM, Martinez del Rio C (1997) Stable isotopes in animal ecology: assumptions, caveats, and a call for more laboratory experiments. Ecology 78:1271-1276 
Gratton C, Donaldson J, Vander Zanden MJ (2008) Ecosystem linkages between lakes and the surrounding terrestrial landscape in Northeast Iceland. Ecosystems 11:764-774

Greenstone MH, Shufran KA (2003) Spider predation: speciesspecific identification of gut contents by polymerase chain reaction. J Arachnology 31:131-134

Hering D, Plachter H (1997) Riparian ground beetles (Coeloptera, Carabidae) preying on aquatic invertebrates: a feeding strategy in alpine floodplains. Oecologia 111:261-270

Hynes HBN (1942) A study of the feeding of adult stoneflies (Plecoptera). Proc R Entomol Soc London Ser A 17:7-9

Hynes HBN (1970) The ecology of running waters. Liverpool University Press, Liverpool

Jackson JK, Fisher SG (1986) Secondary production, emergence, and export of aquatic insects of a Sonoran desert stream. Ecology 67:629-638

Kato C, Iwata T, Wada E (2004) Prey use by web-building spiders: stable isotope analyses of trophic flow at a forest-stream ecotone. Ecol Res 19:633-643

Kovats ZE, Ciborowski JJH, Corkum LD (1996) Inland dispersal of adult aquatic insects. Freshw Biol 36:265-276

McCutchan JHJ, Lewis WMJ, Kendall C, McGrath CC (2003) Variation in trophic shift for stable isotope ratios of carbon, nitrogen, and sulfur. Oikos 102:378-390

Merritt RW, Cummins KW, Berg MB (2008) An Introduction to the Aquatic Insects of North America. Kendall/Hunt Publishing Company, Dubuque

Minagawa M, Wada E (1984) Stepwise enrichment of $15 \mathrm{~N}$ along food chains: further evidence and the relation between $\delta 15 \mathrm{~N}$ and animal age. Geochim Cosmochim Acta 48(5):1135-1140

Murakami M, Nakano S (2002) Indirect effect of aquatic insect emergence on a terrestrial insect population through by birds predation. Ecol Lett 5:333-337

Nakano S, Murakami M (2001) Reciprocal subsidies: dynamic interdependence between terrestrial and aquatic food webs. Proc Nat Acad Sci 98:166-170

Nakano S, Miyasaka H, Kuhara N (1999) Terrestrial-aquatic linkages: riparian arthropod inputs alter trophic cascades in a stream food web. Ecology 80:2435-2441

Nentwig W (1980) The selective prey of linyphiid-like spiders and of their space webs. Oecologia 45:236-243

Nentwig W (1982) Epigeic spiders, their potential prey and competitors: relationship between size and frequency. Oecologia 55: 130-136

Ostrom PH, Colunga-Garcia M, Gage SH (1997) Establishing pathways of energy flow for insect predators using stable isotope ratios: field and laboratory evidence. Oecologia 109:108-113

Paetzold A, Tockner K (2005) Effects of riparian arthropod predation on the biomass and abundance of aquatic insect emergence. $\mathrm{J} \mathrm{N}$ Am Benthol Soc 24:395-402

Paetzold A, Schubert CJ, Tockner K (2005) Aquatic terrestrial linkages along a braided-river: riparian arthropods feeding on aquatic insects. Ecosystems 8:748-759

Paetzold A, Bernet JF, Tockner K (2006) Consumer-specific responses to riverine subsidy pulses in a riparian arthropod assemblage. Freshw Biol 51:1103-1115

Paetzold A, Lee M, Post D (2008) Marine resource flows to terrestrial arthropod predators on a temperate island: the role of subsidies between systems of similar productivity. Oecologia 157:653-659

Parnell AC, Inger R, Bearhop S, Jackson AL (2010) Source partitioning using stable isotopes: coping with too much variation. PLoS ONE 5:e9672

Peckarsky BL, Dodson SI, Conklin DJ (1985) A key to the aquatic insects of streams in the vicinity of the Rocky Mountain
Biological Lab including chironomid larvae from streams and ponds. Colorado Division of Wildlife, Colorado

Peckarsky BL, Taylor BW, Caudill CC (2000) Hydrologic and behavioral constraints on oviposition in stream insects: implications for adult dispersal. Oecologia 125:186-200

Peckarsky BL, McIntosh A, Caudill CC, Dahl J (2002) Swarming and mating behavior of a mayfly Baetis bicaudatus suggest stabilizing selection for male body size. Behav Ecol Sociobiol 51: 530-537

Petersson E, Hasselrot AT (1994) Mating and nectar feeding in the psychomyiid caddisfly Tinodes waeneri. Aquat Insects 16:177-187

Pinder LCV (1986) Biology of freshwater Chironomidae. Annu Rev Entomol 31:1-23

Polis GA, Anderson WB, Holt RD (1997) Toward an integration of landscape and food web ecology: the dynamics of spatially subsidized food webs. Annu Rev Ecol Syst 28:289-316

Post DM (2002) Using stable isotopes to estimate trophic position: models, methods, and asssumptions. Ecology 83:703-718

Power ME, Rainey WE, Parker MS, Sabo JL, Smyth A, Khandwala S et al (2004) River-to-watershed subsidies in an old-growth conifer forest. In: Polis GA, Power ME, Huxel GR (eds) Food webs at landscape level. University of Chicago Press, Chicago, pp 217-240

R Core Team (2012) R: A language and environment for statistical computing. R Foundation for Statistical Computing, Vienna, Austria. ISBN 3-900051-07-0. http://www.R-project.org/

Sabo JL, Power ME (2002) Numerical response of lizards to aquatic insects and short-term consequences for terrestrial prey. Ecology 83:3023-3036

Sanzone DM, Meyer JL, Marti E, Gardiner EP, Tank JL, Grimm NB (2003) Carbon and nitrogen transfer from a desert stream to riparian predators. Oecologia 134:238-250

Schlee D (1977) Florale und extraflorale Nektarien sowie Insektenkot als Nahrungsquelle für Chironomidae Imagines (und andere Diptera). Stuttg Beitr Naturk Ser A 300:1-15

Sepulveda AJ, Lowe AJ, Marra PP (2012) Using stable isotopes to test for trophic niche partitioning: a case study with stream salamanders and fish. Freshw Biol 57:1399-1409

Sulzman EW (2007) Stable isotope chemistry and measurement: a primer. In: Michener R, Lajtna K (eds) Stable isotopes in ecology and environmental science, 2nd edn. Blackwell Publishing, Oxford, pp 1-21

Ubick D, Paquin P, Cushing PE, Roth V (2005) Spiders on North America: an identification manual. American Arachnological Society, Keene (New Hampshire)

Vander Zanden JM, Rasmussen JB (1999) Primary consumer delta $13 \mathrm{C}$ and delta $15 \mathrm{~N}$ and the trophic position of aquatic consumers. Ecology 80:1395-1404

Wallace JB, Eggert SL, Meyer JL, Webster JR (1997) Multiple trophic levels of a forest stream linked to terrestrial litter inputs. Science 277:102-104

Walters DM, Fritz KM, Otter RR (2008) The dark side of subsidies: adult stream insects export organic contaminants to riparian predators. Ecol Appl 18:1835-1841

Winterbourn MJ (2005) Dispersal feeding and parasitism of adult stoneflies (Plecoptera) at a New Zealand forest stream. Aquat Insects 27:155-166

Wise DH (1993) Spiders in ecological webs. Cambridge University Press, Cambridge

Wise DH, Moldendhauer DM, Halaj J (2006) Using stable isotopes to reveal shifts in prey consumption by generalist predators. Ecol Appl 16:865-876 